Cite this: Phys. Chem. Chem. Phys., 2014, 16, 13616

Received 20th January 2014, Accepted 27th February 2014 DOI: $10.1039 / \mathrm{c} 4 \mathrm{cp} 00304 \mathrm{~g}$ www.rsc.org/pccp

\section{Formic acid electrooxidation on thallium-decorated shape-controlled platinum nanoparticles: an improvement in electrocatalytic activity}

\author{
Carlos Busó-Rogero, Juan V. Perales-Rondón, Manuel J. S. Farias, \\ Francisco J. Vidal-Iglesias, Jose Solla-Gullon, Enrique Herrero and Juan M. Feliu*
}

\begin{abstract}
Thallium modified shape-controlled Pt nanoparticles were prepared and their electrocatalytic activity towards formic acid electrooxidation was evaluated in $0.5 \mathrm{M}$ sulfuric acid. The electrochemical and in situ FTIR spectroscopic results show a remarkable improvement in the electrocatalytic activity, especially in the low potential region (around 0.1-0.2 V vs. RHE). Cubic Pt nanoparticles modified with $\mathrm{Tl}$ were found to be more active than the octahedral $\mathrm{Pt}$ ones in the entire range of $\mathrm{Tl}$ coverages and potential windows. In situ FTIR spectra indicate that the promotional effect produced by TI results in the inhibition of the poisoning step leading to $\mathrm{CO}_{a d s}$ thus improving the onset potential for the complete formic acid oxidation to $\mathrm{CO}_{2}$. Chronoamperometric experiments were also performed at $0.2 \mathrm{~V}$ to evaluate the stability of the electrocatalysts at constant potential. Finally, experiments with different concentrations of formic acid (0.05-1 M) were also carried out. In all cases, Tl-modified cubic Pt nanoparticles result to be the most active. All these facts reinforce the importance of controlling the surface structure of the electrocatalysts to optimize their electrocatalytic properties.
\end{abstract}

\section{Introduction}

Formic acid is among the most promising fuels for anodic reactions in electrochemical energy conversion devices such as Polymer Electrolyte Membrane (PEM) fuel cells. ${ }^{1,2}$ Assuming that the change in the Gibbs free energy for the reaction in the fuel cell $\left(\mathrm{HCOOH}+1 / 2 \mathrm{O}_{2} \rightarrow \mathrm{CO}_{2}+\mathrm{H}_{2} \mathrm{O}\right)$ is $\Delta G^{\mathrm{O}} \approx-285 \mathrm{~kJ} \mathrm{~mol}^{-1}$, the standard electrode potential for the formic acid/ $/ \mathrm{CO}_{2}$ redox couple is $c a$. $-0.25 \mathrm{~V}$. However, formic acid electro-oxidation takes place at potentials that are $0.6 \mathrm{~V}$ higher than the reversible thermodynamic potential on platinum electrodes. ${ }^{4,5}$ From an electrocatalytic point of view, this large overpotential is mainly due to the high resistance to the oxidation of intermediate products that diminish the performance of platinum as an anode catalyst by blocking surface sites. ${ }^{6}$ In this sense, many studies on formic acid electro-oxidation reaction aim at developing new electrocatalytic materials which present higher selectivity than platinum electrodes for the formic acid dissociation. In this respect, the mechanism of formic acid electro-oxidation occurs through two parallel routes on platinum electrodes. ${ }^{7-11}$ In one of these pathways, $\mathrm{HCOOH}$ is oxidized through an active intermediate, which decomposes to yield $\mathrm{CO}_{2}$. In the other reaction pathway, i.e. the indirect one, the reaction mechanism occurs through the

Instituto de Electroquímica, Universidad de Alicante, Ap. 99 E-03080, Alicante, Spain.E-mail: juan.feliu@ua.es non-faradaic dehydration reaction of formic acid yielding $\mathrm{CO}_{\mathrm{ads}}$ and water molecules. The latter reaction also takes place at open circuit potential on platinum ${ }^{12}$ and requires more surface sites than the active intermediate reaction path. ${ }^{13}$ Since the oxidation of $\mathrm{CO}_{\text {ads }}$ requires a large overpotential, this species is considered to be a poisoning intermediate.

It is also known that the formic acid electro-oxidation reaction is very sensitive to the local surface structure. ${ }^{5,14,15}$ Concerning this point, it was shown that the $\mathrm{Pt}(100)$ electrode was the most active among platinum basal planes, while the activity was observed for $\mathrm{Pt}(111)$ for both routes. ${ }^{5}$ To modify the electrocatalytic activity and/or selectivity of bare substrates for the different routes, the presence of other species such as foreign atoms is a powerful strategy. In fact, many studies on modified single crystal Pt electrodes with $\mathrm{Sb},{ }^{16} \mathrm{Bi}^{17}{ }^{17} \mathrm{~Pb},{ }^{18} \mathrm{Pd}^{19}$ and $\mathrm{Te}^{20}$ show an improvement in the catalytic performance of these materials towards formic acid oxidation. These electrocatalytic improvements by foreign atoms are possible due to: (i) a thirdbody effect, where adatoms block neighboring sites required for $\mathrm{CO}_{\mathrm{ads}}$ formation; ${ }^{13}$ (ii) electronic effects, where the foreign adatoms modify the adsorption energy between the adsorbate and the substrate facilitating the oxidation reaction; ${ }^{12,13,21}$ and (iii) a bifunctional mechanism, where, in this case, the presence of foreign atoms can reduce the overpotential for $\mathrm{CO}_{\text {ads }}$ oxidation providing easily activated oxygen-species at lower potentials than those on the corresponding bare substrate. ${ }^{22}$ 
From an applied point of view, the use of single crystal surfaces is not feasible and nanomaterials with a much higher surface to volume ratio are required. Since the development of methods to synthesize shape-controlled Pt nanoparticles ${ }^{23}$ and their first use in electrocatalysis, ${ }^{24}$ many studies have been focused on the evaluation of the electrocatalytic properties of these shaped Pt particles for oxidation reactions of promising fuels, such as formic acid. ${ }^{25,26}$ For this reaction, shape-controlled Pt nanoparticles have confirmed the structural electrocatalytic dependence related to the presence of facets with (100) and (111) symmetry. Thus, Pt nanoparticles rich in (100) facets are the most electroactive applicable system towards formic acid oxidation. Unfortunately, shaped Pt nanoparticles also show a high CO poisoning rate. ${ }^{26}$

As has been done with platinum single crystals, in order to increase the activity and/or to overcome the poisoning effect, $\mathrm{Pt}$ nanoparticles have been decorated with adatoms such as $\mathrm{Pd},{ }^{27,28} \mathrm{Bi}^{29,30}$ or $\mathrm{Sb}^{31}$ In addition, Pt/Pd alloyed ${ }^{32}$ and PtBi intermetallic nanoparticles ${ }^{33}$ have also been tested. Based on the reported results in ref. 28 and 29 it can be proposed that the improvement in electrocatalytic activity seems to be mainly related to the geometry of the surface atoms of the shaped nanoparticles and the chemical nature of foreign adatoms.

Studies in the 1980s showed that thallium (Tl) UPD (under potential deposition) on both polycrystalline platinum and gold increases the rate of formaldehyde electro-oxidation. ${ }^{34,35}$ However, even considering these promising results, almost no studies have been devoted to the impact of $\mathrm{Tl}$ in the electrocatalysis of formic acid. ${ }^{36}$ For that reason, we report in this paper an electrochemical and spectroscopic (in situ FTIR - Fourier Transform Infrared) study on the electrocatalytic properties of Tl-decorated shape-controlled $\mathrm{Pt}$ nanoparticles towards $\mathrm{HCOOH}$ electrooxidation.

\section{Experimental}

Platinum single crystal surfaces were prepared following the method developed by Clavilier et al. ${ }^{37}$ from single crystal beads (ca. $2 \mathrm{~mm}$ in diameter). Before the experiments, working electrodes were flame annealed during $30 \mathrm{~s}$, cooled down in a $\mathrm{H}_{2} / \mathrm{Ar}$ atmosphere and quenched in ultrapure water in equilibrium with this atmosphere before they were transferred to the electrochemical cell. ${ }^{38}$ Cubic and octahedral shape-controlled Pt nanoparticles, denoted as (100)Pt and (111)Pt respectively, were employed. The synthesis of these shape-controlled $\mathrm{Pt}$ nanoparticles was performed as previously described in detail. ${ }^{39}$ Transmission Electron Microscopy (TEM) measurements were performed to estimate both particle size and morphology/ shape. $^{39}$

For electrochemical and in situ FTIR measurements, the nanoparticles dispersed in water were deposited on a polished gold disk and dried under argon atmosphere. Thereafter, the nanoparticles were cleaned by CO (N47, Air Liquide) monolayer adsorption and stripping treatment before the experiments, avoiding high potential excursions to preserve surface order.
The active area of platinum nanoparticles was calculated by measuring the charge involved in the so-called hydrogen UPD region after the subtraction of the conventional double-layer contribution in $0.5 \mathrm{M} \mathrm{H}_{2} \mathrm{SO}_{4}$ solution, using a reference value of $0.23 \mathrm{mC} \mathrm{cm}^{-2}$. ${ }^{40}$ A small quantity of nanoparticles (with an active area of $c a .0 .05-0.1 \mathrm{~cm}^{2}$ ) was deposited in all the experiments in order to avoid/minimize transport problems of the reactant species to the surface of the nanoparticles. ${ }^{41}$

The deposition of $\mathrm{Tl}$ on $\mathrm{Pt}$ was performed using dilute concentrations of $10^{-4}-10^{-5} \mathrm{M} \mathrm{Tl}_{2} \mathrm{SO}_{4}$ (Aldrich ${ }^{\circledR} 99.995 \%$ ) in $0.5 \mathrm{M} \mathrm{H}_{2} \mathrm{SO}_{4}$ solution, cycling the electrode potential between $0.06 \mathrm{~V}$ and $0.90 \mathrm{~V}$ at $0.05 \mathrm{~V} \mathrm{~s}^{-1}$. The $\mathrm{Tl}$ coverage was monitored through the decrease of the hydrogen adsorption/desorption peaks, according to the equation:

$$
\theta_{\mathrm{Tl}}=1-\theta_{\mathrm{H}}=\frac{q_{\mathrm{H}}^{0}-q_{\mathrm{H}}^{\mathrm{Tl}}}{q_{\mathrm{H}}^{0}}
$$

where $q_{\mathrm{H}}^{0}$ and $q_{\mathrm{H}}^{\mathrm{Tl}}$ are the hydrogen adsorption charges of the clean and thallium modified electrodes respectively, which were also calculated after the subtraction of the double layer charging contribution. In the case of platinum single crystals, the electrodes were cycled in specific potential ranges to preserve the surface order and to avoid problems of $\mathrm{Tl}$ desorption at higher potentials.

A platinum wire was used as a counter electrode, and a reversible hydrogen (N50, Air Liquide) electrode (RHE) was employed as a reference electrode. All potentials used in this paper are referenced to the RHE. Experiments were carried out in $0.5 \mathrm{M} \mathrm{H}_{2} \mathrm{SO}_{4}$ (Merck KGaA Suprapur ${ }^{\circledR}$ 96\%), prepared in ultrapure water (Elga PureLab Ultra 18.2 $\mathrm{M} \Omega \mathrm{cm}$ ), and deareated with Ar (N50, Air Liquide). Formic acid (Merck KGaG 98\%) oxidation experiments were performed in $0.5 \mathrm{M} \mathrm{H}_{2} \mathrm{SO}_{4}$.

For electrochemical measurements, cyclic voltammetry and chronoamperometry were employed using a waveform generator (EG\&G PARC 175) together with a potentiostat (eDAQ EA161) and a digital recorder (eDAQ ED401).

In situ FTIR spectra were acquired using a Nicolet (Model 8700) spectrometer, equipped with an MCT (MercuryCadmium-Telluride) detector. The spectroelectrochemical cell was fitted with a prismatic $60^{\circ} \mathrm{CaF}_{2}$ window, as described previously. ${ }^{42}$ The spectra, obtained from the average of 100 interferograms using a resolution of $8 \mathrm{~cm}^{-1}$, were collected at intervals of $50 \mathrm{mV}$ between $0.05 \mathrm{~V}$ to $0.90 \mathrm{~V}$ vs. RHE. For all experiments, p-polarized light was employed, which allows detecting changes in the concentration of active species on the electrode surface and electrolyte solution. ${ }^{42}$ Spectra are presented in absorbance units $\left[A=-\log \left(\frac{R_{1}-R_{2}}{R_{1}}\right)\right]$ in which $R_{2}$ and $R_{1}$ are referred to as the reflectance values of the single beam spectra corresponding to the sample and the reference potentials, respectively. Positive bands in the spectra are related to species that have been formed at the sample potential whereas negative bands correspond to species consumed. All the experiments were performed at room temperature. 


\section{Results and discussion}

\section{Formic acid oxidation on Tl-modified Pt single crystal electrodes}

Preliminary experiments with Pt(100) and Pt(111) single crystal electrodes were performed to evaluate the effects of the $\mathrm{Tl}$ adsorption on these Pt model surfaces both in the absence and presence of formic acid. Fig. 1 shows voltammetric results for $\mathrm{Tl}$ modified $\mathrm{Pt}(100)$ and $\mathrm{Pt}(111)$ single crystal electrodes in a $0.5 \mathrm{M} \mathrm{H}_{2} \mathrm{SO}_{4}$ solution. The effect of $\mathrm{Tl}$ deposition can be easily monitored by the changes in the cyclic voltammetric profile. In addition, in order to avoid possible Tl dissolution, the upper potential limits were set at 0.65 and $0.6 \mathrm{~V}$ for $\mathrm{Pt}(100)$ and $\mathrm{Pt}(111)$ electrodes, respectively. For the $\mathrm{Pt}(100)$ electrode (Fig. 1a), the adsorption/desorption states between 0.2 and $0.5 \mathrm{~V}$ (which are associated with the competitive adsorption between hydrogen and anions) remarkably decrease during $\mathrm{Tl}$ deposition, whereas a small peak appears at about $0.15 \mathrm{~V}$ at $\mathrm{Tl}$ coverages close to the full blockage. In the case of the $\operatorname{Pt}(111)$ electrode, Fig. 1b, similar effects are observed for the diminution of the charge in the hydrogen adsorption/desorption region (between 0.06 and $0.35 \mathrm{~V}$ ) and the (bi)sulfate adsorption

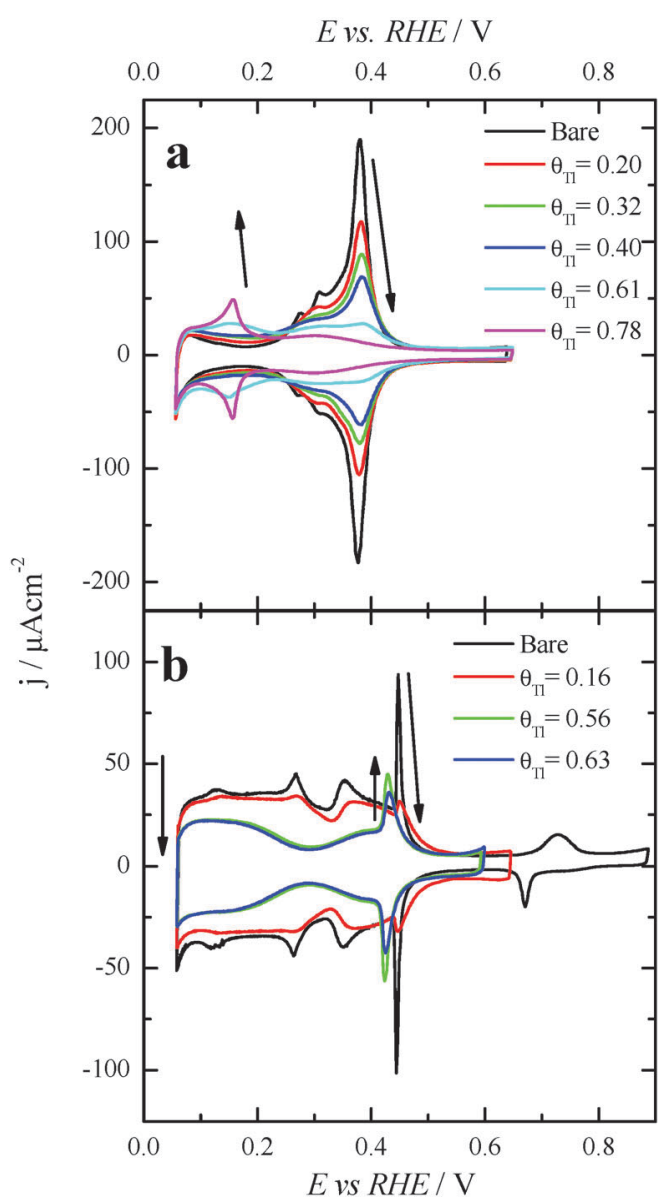

Fig. 1 Evolution of the voltammetric profiles in $0.5 \mathrm{M} \mathrm{H}_{2} \mathrm{SO}_{4}$ with increasing amounts of $\mathrm{Tl}$ on (a) $\mathrm{Pt}(100)$ and (b) $\mathrm{Pt}(111)$. Scan rate: $0.05 \mathrm{~V} \mathrm{~s}^{-1}$. Arrows indicate changes associated with increasing $\mathrm{Tl}$ amounts at the surface. (between 0.35 and $0.65 \mathrm{~V}$ ). Again, a new small peak for this electrode appears at about $0.43 \mathrm{~V}$ at high coverages of $\mathrm{Tl}$. This peak is associated with the adsorption of sulfate on the modified electrode, because it is absent in perchloric acid solutions. Although it appears in the same potential region that the spike in sulfuric acid solutions for the $\mathrm{Pt}(111)$ electrode, the origin is not the same. The spike at $0.45 \mathrm{~V}$ diminishes upon $\mathrm{Tl}$ deposition and at a given $\mathrm{Tl}$ coverage the new peak appears. It is then probably related to structural changes in the adlayer that changes the interaction of sulfate with the electrode surface.

The positive going sweep voltammetric profiles of formic acid oxidation for the same Tl-modified Pt single crystal electrodes from Fig. 1 are presented in Fig. 2, using $0.1 \mathrm{M}$ $\mathrm{HCOOH}$ in $0.5 \mathrm{M} \mathrm{H}_{2} \mathrm{SO}_{4}$ as test solution. As expected, very low currents are observed for the bare $\mathrm{Pt}(100)$ electrode as a consequence of the well-established CO poisoning process coming from the dehydration of formic acid, which is favored on $\mathrm{Pt}(100) .{ }^{11}$ With increasing amounts of $\mathrm{Tl}$, the indirect path (through CO poisoning) is hindered. Then formic acid oxidation can take place through the direct path and oxidation currents increase very significantly. The results suggest an

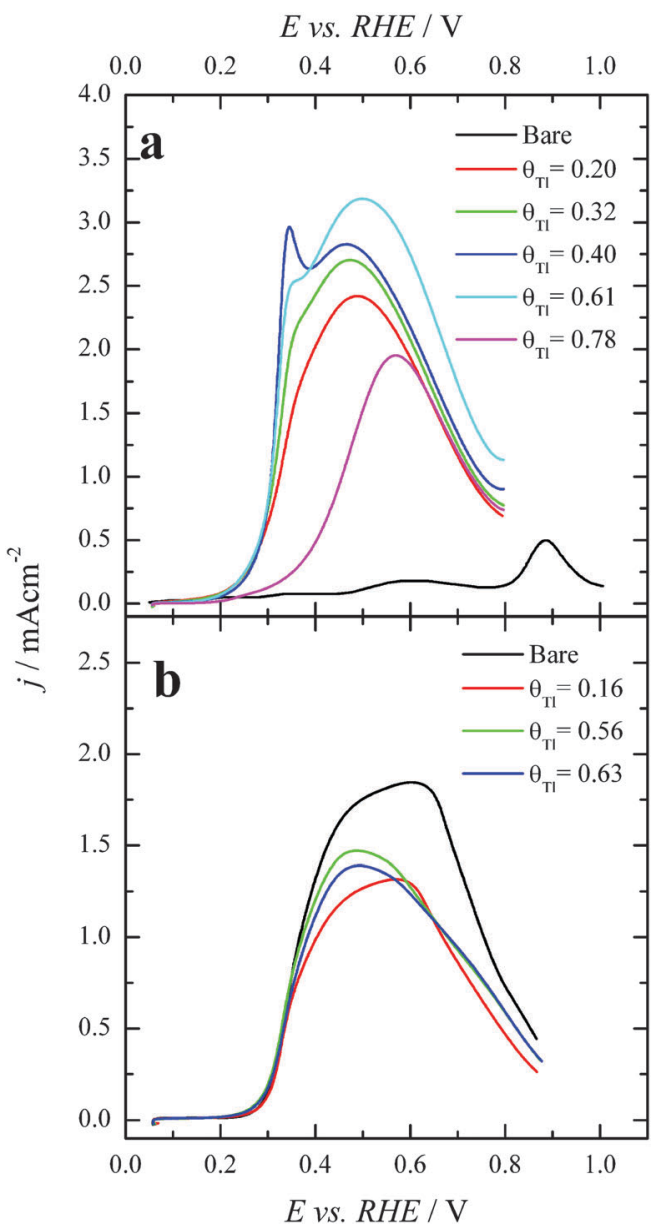

Fig. 2 Positive sweep voltammetric profiles for $0.1 \mathrm{M}$ formic acid oxidation in $0.5 \mathrm{M} \mathrm{H}_{2} \mathrm{SO}_{4}$ with and without $\mathrm{Tl}$ for (a) Pt(100) and (b) Pt(111) single crystals. Scan rate: $0.02 \mathrm{~V} \mathrm{~s}^{-1}$. 
optimum $\mathrm{Tl}$ coverage at values close to 0.4 . At higher coverages, the onset potential increases and the current diminishes.

However, in the case of the $\operatorname{Pt}(111)$ electrode (Fig. 2b), for which it is well-established that the CO poisoning is almost negligible, ${ }^{11}$ the addition of $\mathrm{Tl}$ does not provide significant changes in the electrooxidation process. These results seem to indicate that $\mathrm{Tl}$ acts as a third body preventing the dehydration reaction. For the $\mathrm{Pt}(111)$ electrode, owing to the almost negligible CO formation rate, ${ }^{5}$ the presence of $\mathrm{Tl}$ does not improve its catalytic activity. The current diminution for this electrode is just the result of the diminution of the Pt free sites. On the other hand, the increase of activity for the Pt(100) electrode can be related to the diminution of the $\mathrm{CO}_{\text {ads }}$ coverage which leads to an increase of the oxidation through the active intermediate reaction path. However, electronic effects cannot be discarded for this electrode. It should be noted that the onset for the direct oxidation reaction in the absence of poison on the $\mathrm{Pt}(100)$ electrode is $0.30 \mathrm{~V}$ (see ref. 43), whereas in the presence of $\mathrm{Tl}$ the onset is $c a .0 .20 \mathrm{~V}$. This diminution of the onset potential at a $\mathrm{Tl}$ coverage of $c a$. 0.4 suggests the possible presence of an electronic effect. These results also point out the importance of controlling the surface structure of the Pt substrate, the $\operatorname{Pt}(100)$ square structure being much more convenient than the hexagonal $\operatorname{Pt}(111)$. Thus, in terms of the particle shape, it would be preferable to use cubic Pt nanoparticles in which the number of $\{100\}$ surface sites is maximized. ${ }^{44}$

\section{Electrochemical characterization of Tl modified Pt nanoparticles}

Fig. 3 displays the voltammetric profiles of the (100)Pt and (111)Pt nanoparticles before and after $\mathrm{Tl}$ incorporation. Before the Tl decoration, the voltammetric profiles of the cubic and octahedral Pt nanoparticles are those that are expected from their shape-surface structure relationship. ${ }^{45}$ Thus, the cubic Pt nanoparticles show the main features related to a preferential $\{100\}$ surface structure, that is, a sharp peak at $\sim 0.27 \mathrm{~V}$ related to $\{100\}$ edge/corner sites and a signal around $0.37 \mathrm{~V}$ associated with wide $\{100\}$ terrace sites. In contrast, the octahedral nanoparticles show the characteristics of a preferential $\{111\}$ surface structure, with a broad peak at about $0.52 \mathrm{~V}$ related to sulfate adsorption on relatively wide two-dimensional $\{111\}$ terrace sites. A detailed analysis of the characteristic voltammetric features of similar shape-controlled Pt nanoparticles was described in previous contributions. ${ }^{44}$

Fig. 3 also shows the voltammetric responses of the (100)Pt and (111)Pt nanoparticles after partial and maximum deposition of Tl. The evolution of the voltammetric profiles is similar to those previously reported for Pd and $\mathrm{Bi}$ on shape-controlled Pt nanoparticles ${ }^{28,29}$ or after deposition of $\mathrm{Bi}(\mathrm{III})$, Te(IV) and $\mathrm{Se}(\mathrm{Iv})$ on stepped Pt surfaces. ${ }^{46}$ In addition, the $\mathrm{Tl}$ adsorption process does not produce appreciable changes in the charge density on the so-called double layer region until high thallium coverages are reached. As described in the experimental section, the $\mathrm{Tl}$ coverage can be calculated considering the expression $\theta_{\mathrm{Tl}}=1-\theta_{\mathrm{H}}$, where $\theta_{\mathrm{Tl}}$ and $\theta_{\mathrm{H}}$ are the thallium and hydrogen coverages, respectively. However, at the maximum

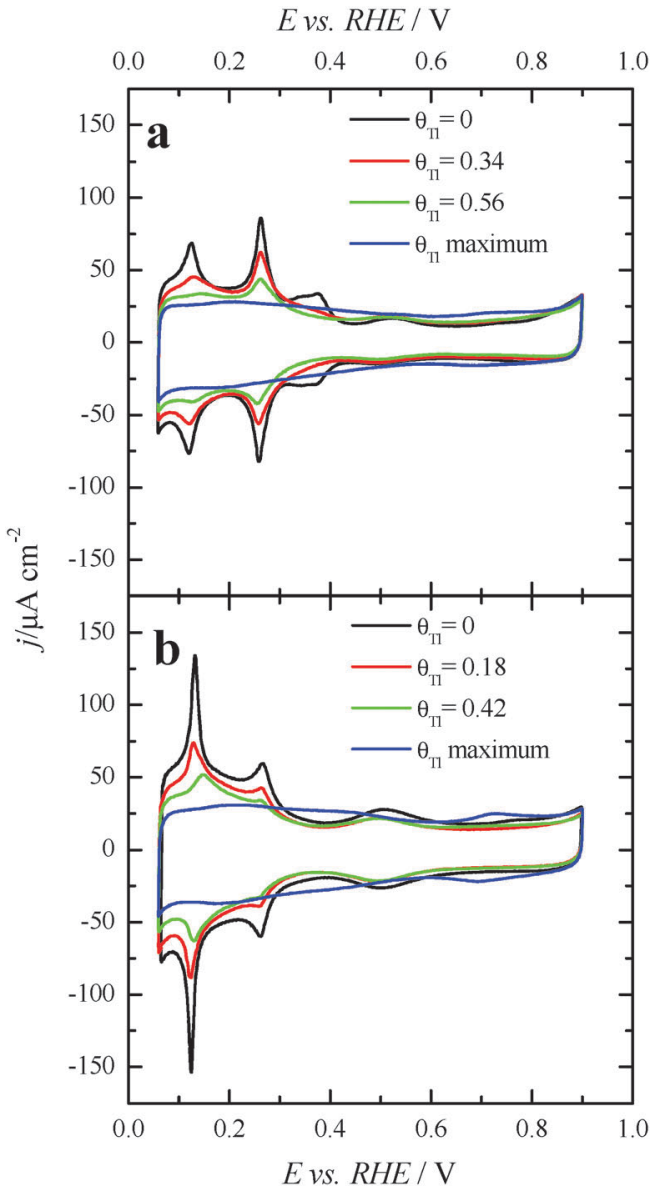

Fig. 3 Voltammetric profiles for increasing amounts of $\mathrm{Tl}$ coverages on (a) (100)Pt and (b) (111)Pt nanoparticles in $0.5 \mathrm{M} \mathrm{H}_{2} \mathrm{SO}_{4}+10^{-4}-10^{-5} \mathrm{M}$ $\mathrm{Tl}_{2} \mathrm{SO}_{4}$. Scan rate: $0.05 \mathrm{~V} \mathrm{~s}^{-1}$.

thallium coverage on both Pt nanoparticles, Fig. 3, an important increase of the double layer region is observed. This fact prevents an accurate determination of the $\mathrm{Tl}$ coverage for highly covered surfaces that cannot be properly calculated. For that reason, the maximum coverage for each sample will be referred to as "maximum" and no numeric value will be given. In addition, it is important to note the absence of additional voltammetric features at high coverages and remark that only a small broad peak is visible at about $0.70 \mathrm{~V}$, particularly in the preferential (111)Pt nanoparticles. This feature can be linked to the thallium desorption from $\{111\}$ terrace sites, as pointed out for Tl UPD in Pt(111) reports. ${ }^{47,48}$

\section{Formic acid oxidation on Tl modified shape controlled Pt nanoparticles}

After each particular $\mathrm{Tl}$ adsorption, the modified Pt nanoparticles were transferred to a second electrochemical cell containing $0.1 \mathrm{M}$ formic acid $+0.5 \mathrm{M} \mathrm{H}_{2} \mathrm{SO}_{4}$. Fig. 4 compares the positive going sweep voltammetric responses obtained for the bare and $\mathrm{Tl}$ modified shaped nanoparticles. For the bare cubic (100)Pt nanoparticles (Fig. 4a, black line), the positive going scan shows almost zero current density at potentials below $0.35 \mathrm{~V}$, due to $\mathrm{CO}$ poisoning effects. The $\mathrm{HCOOH}$ 


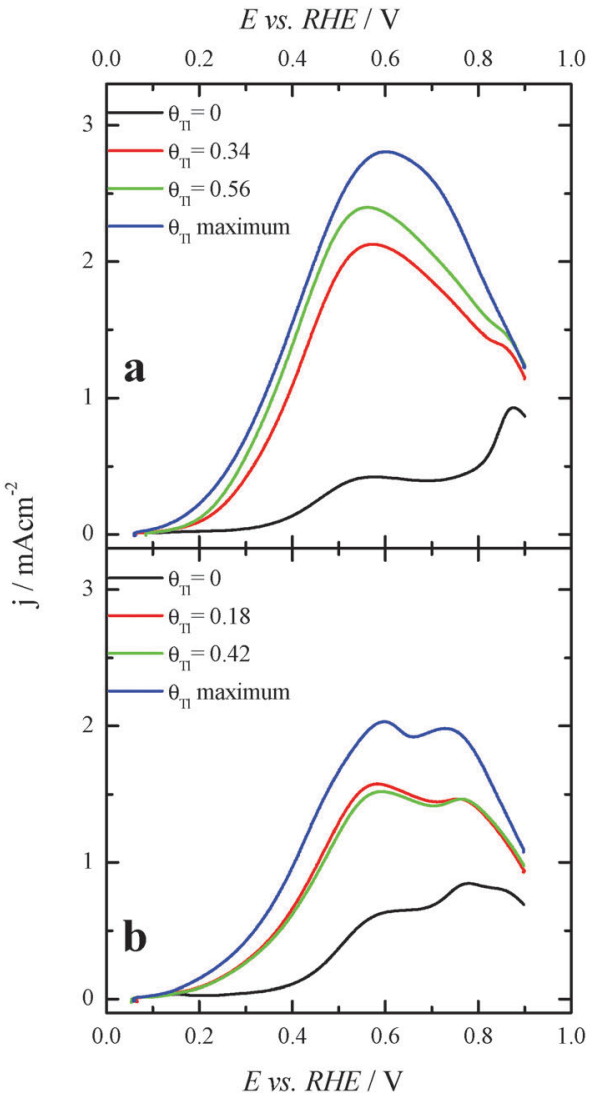

Fig. 4 Positive sweep voltammetric profiles for formic acid electrooxidation with increasing amounts of Tl coverages for (a) (100)Pt and (b) (111)Pt nanoparticles. Scan rate: $0.02 \mathrm{~V} \mathrm{~s}^{-1}$. Test solution: $0.1 \mathrm{M}$ formic acid in $0.5 \mathrm{M} \mathrm{H}_{2} \mathrm{SO}_{4}$.

oxidation starts at around $0.35 \mathrm{~V}$, and the current density increases slowly until $\sim 0.80 \mathrm{~V}$. Above this potential, the current density starts to grow rapidly due to $\mathrm{CO}$ oxidation and therefore in the reverse scan the current density would be much higher as the surface is CO-free. As before, these negative-going results are not shown, because they are irrelevant in electrocatalytic studies. ${ }^{26,39}$ Interestingly, for Tl modified cubic (100) Pt nanoparticles with $\theta_{\mathrm{Tl}}=0.34$ and 0.56 , Fig. $4 \mathrm{a}$ (red and green lines, respectively), the onset potential of $\mathrm{HCOOH}$ oxidation remarkably decreases to about $0.1 \mathrm{~V}$. Moreover, at the maximum coverage (blue line), the onset potential is even lower (about $0.08 \mathrm{~V}$ ). This feature clearly evidences the positive impact of thallium on the electro-oxidation of formic acid in the low potential region.

For the (111)Pt nanoparticles, Fig. 4b, a similar effect on the onset potential is observed after surface decoration with Tl. Taking into account that (i) the $\{111\}$ domains do not suffer the same strong CO poisoning effect as that observed with the $\{100\}$ domains, ${ }^{11}$ (see Fig. 2), and (ii) the $\{111\}$ domains have a low catalytic activity for the direct oxidation, ${ }^{5}$ the electrocatalytic enhancement observed is lower than that reported for the (100)Pt nanoparticles. Anyhow, the onset potential diminishes when $\theta_{\mathrm{T} 1}$ increases, decreasing to around $0.1 \mathrm{~V}$ at the maximum coverage (blue line). Also, the onset for the formic acid oxidation

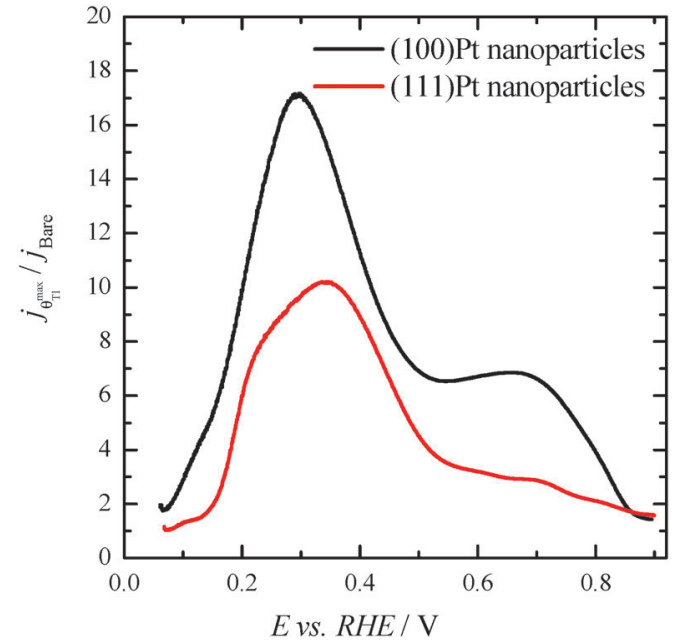

Fig. 5 Ratio between the $\mathrm{HCOOH}$ oxidation current densities obtained using the bare and $\mathrm{Tl}$-decorated (maximum coverage) shape-controlled Pt nanoparticles. Data taken from Fig. 4.

observed for the Tl modified nanoparticles at high coverages is ca. $0.2-0.3 \mathrm{~V}$ lower than the onset for the direct oxidation route in the unmodified nanoparticles. ${ }^{26}$

Finally, with the aim of comparing the activity of both samples in the whole potential range, Fig. 5 displays the $\mathrm{HCOOH}$ activity ratio between the bare and Tl modified (maximum coverage) Pt nanoparticles. From Fig. 5, it is evident that the "improvement factor" due to the presence of Tl for the (100)Pt nanoparticles is larger than that obtained with the (111)Pt nanoparticles in the entire potential range. In fact, the highest ratio between both activities is observed at $c a .0 .3 \mathrm{~V}$, the potential at which the $\{100\}$ domains have the greatest activity, in agreement with the large catalytic activity of $\mathrm{Tl}$ on the $\{100\}$ domains (Fig. 2a). In addition, in terms of maximum currents, the electrooxidation activity of the Tl-modified (100)Pt nanoparticles is always higher (about 1.5 times) than that of the (111)Pt nanoparticles, Fig. 6.

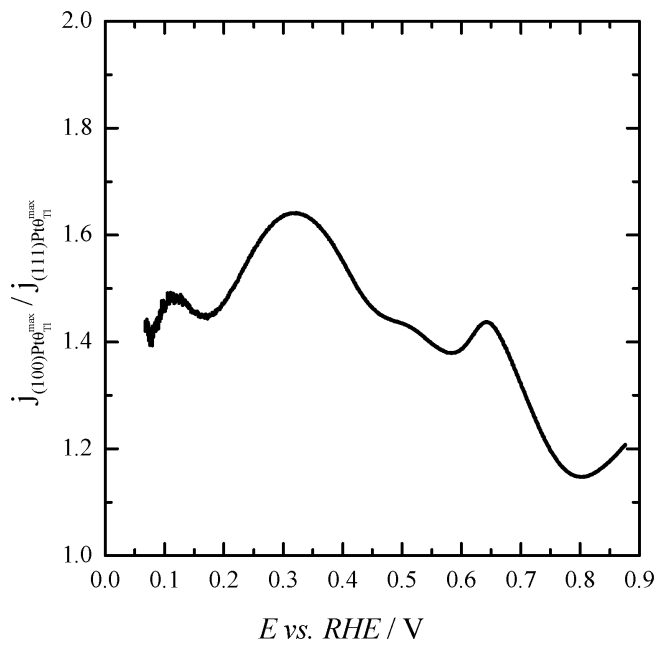

Fig. 6 Ratio between the $\mathrm{HCOOH}$ oxidation current densities obtained using Tl-modified (maximum coverage) (100) and (111)Pt nanoparticles. Data taken from Fig. 4. 


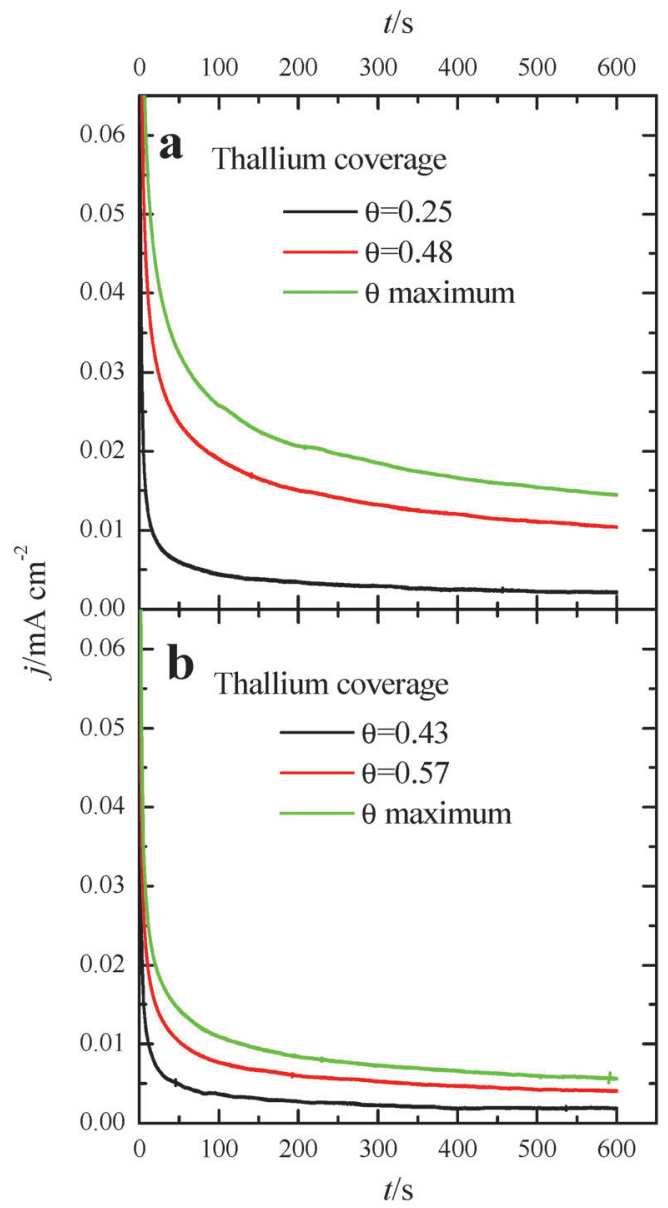

Fig. 7 Current transients recorded at $0.2 \mathrm{~V}$ for formic acid electrooxidation for (a) (100)Pt and (b) (111)Pt nanoparticles with different $\mathrm{Tl}$ coverages. Test solution: $0.1 \mathrm{M}$ formic acid in $0.5 \mathrm{M} \mathrm{H}_{2} \mathrm{SO}_{4}$.
In order to better evaluate the activity as well as the stability of the Tl-modified samples, current transient responses for each modified electrode were recorded at $0.2 \mathrm{~V}$, (Fig. 7), a reasonably low potential value. In these experiments, a pretreatment consisting of a potential step at $0.85 \mathrm{~V}$ for $10 \mathrm{~s}$ prior to the potential step at $0.2 \mathrm{~V}$ was performed in order to oxidize all the possible CO blocking surface sites. ${ }^{26}$ Current transients for the bare nanoparticles are not reported, as current densities for both samples are almost zero. This is due to the fact that the CO formation rate is very high and the surface is immediately covered by CO after the cleaning step. For Tl modified (100)Pt nanoparticles (Fig. 7a), the current densities after $600 \mathrm{~s}$ are $0.002,0.010$ and $0.014 \mathrm{~mA} \mathrm{~cm}^{-2}$ at $\mathrm{Tl}$ coverages of $0.25,0.48$ and the maximum one, respectively. For $\mathrm{Tl}$ modified (111)Pt nanoparticles (Fig. 7b), reactivity is lower and current densities of $0.002,0.004$ and $0.006 \mathrm{~mA} \mathrm{~cm}^{-2}$ were obtained at coverages of $0.43,0.57$ and the maximum one, respectively. These results indicate that $\mathrm{Tl}$ adsorbed on the surface successfully hinders the CO adsorption through the poisoning pathway, and this effect increases with the Tl coverage.

\section{FTIR experiments of formic acid oxidation on Tl-decorated Pt nanoparticles}

In situ FTIR spectra were measured in order to better understand the role of $\mathrm{Tl}$ in the enhancement of formic acid oxidation on the modified nanoparticles. Only the (100)Pt nanoparticles were studied because these nanoparticles present more $\mathrm{CO}_{\mathrm{ads}}$ than the (111)Pt nanoparticles, ${ }^{39,49}$ and then, it is easier to determine the electrocatalytic effects induced by the presence of Tl. Spectra were collected in $0.05 \mathrm{M}$ formic acid in $0.1 \mathrm{M} \mathrm{H}_{2} \mathrm{SO}_{4}$ on non-modified and Tl-modified electrodes (at maximum thallium coverage). Formic acid concentration was diminished with the aim of decreasing the huge amount of $\mathrm{CO}_{2}$ formed during formic acid oxidation, which destabilizes the thin-layer configuration.

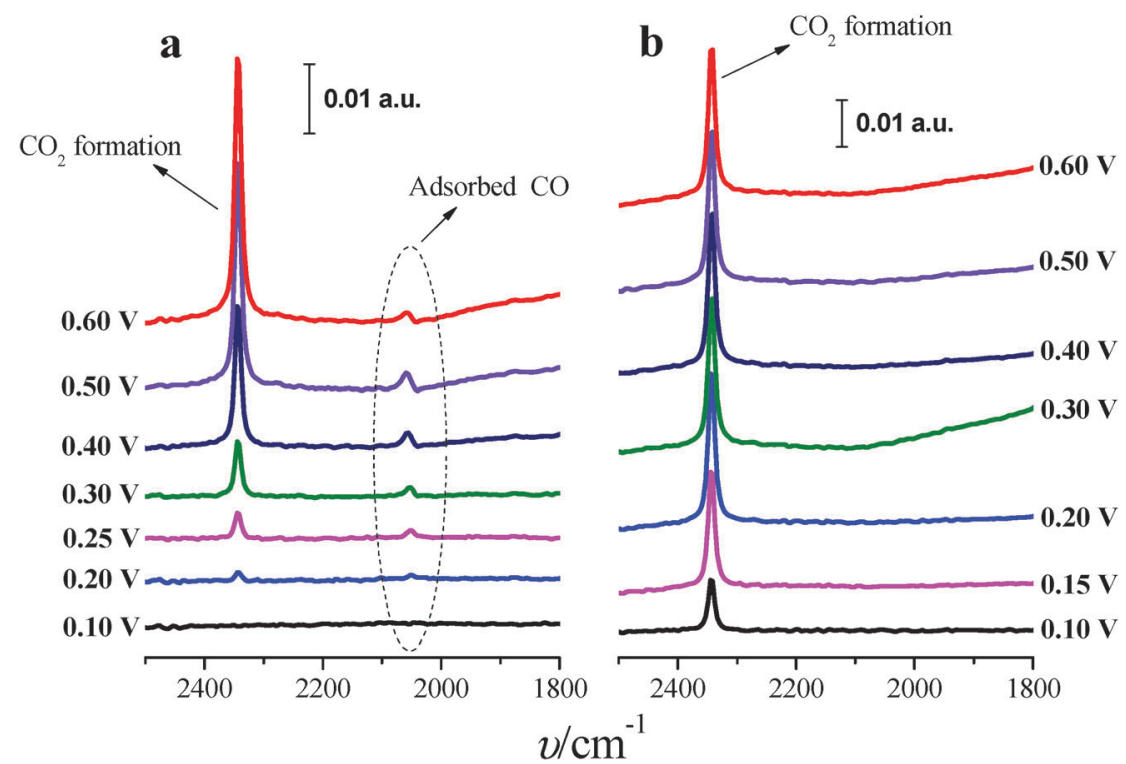

Fig. 8 In situ FTIR spectra for formic acid electro-oxidation on (100)Pt nanoparticles: (a) bare Pt and (b) maximum Tl coverage. Reference spectra were taken at $0.05 \mathrm{~V}$. Test solution: $0.05 \mathrm{M}$ formic acid in $0.1 \mathrm{M} \mathrm{H}_{2} \mathrm{SO}_{4}$. 
Sulfuric acid concentration was also reduced in order to avoid possible damage in the $\mathrm{CaF}_{2}$ prism. For all spectra presented, the spectrum acquired at $0.05 \mathrm{~V}$ was used as a reference.

Fig. 8a displays the spectra for formic acid oxidation on (100)Pt bare nanoparticles. From $0.2 \mathrm{~V}$ to $0.6 \mathrm{~V}$, the spectra show the linearly adsorbed CO band between 2050 and $2060 \mathrm{~cm}^{-1} .^{42}$ At $0.2 \mathrm{~V}$, the band frequency is around $2052 \mathrm{~cm}^{-1}$, whereas at $0.6 \mathrm{~V}$ the frequency shifts to $2060 \mathrm{~cm}^{-1}$, likely due to the Stark effect. ${ }^{50}$ Between 0.4 and $0.5 \mathrm{~V}$, the band shows a slightly bipolar character, meaning that adsorbed $\mathrm{CO}$ was present in the reference potential $(0.05 \mathrm{~V}) .{ }^{42}$ At around $0.2 \mathrm{~V}$, a new band at $2343 \mathrm{~cm}^{-1}$ appears, which is associated with the start of $\mathrm{CO}_{2}$ formation. ${ }^{42}$ The spectra do not show any signal band that could be attributed to bridge adsorbed CO, which should appear at around $1820 \mathrm{~cm}^{-1}$ as was observed for formic acid oxidation in ATR-SEIRA (Attenuated Total Reflection - Surface Enhanced InfraRed Absorption) experiments on thin-film polycrystalline platinum electrodes at $0.35 \mathrm{~V}$ vs. RHE. ${ }^{9}$

Fig. $8 \mathrm{~b}$ shows the spectra for formic acid oxidation on Tl-modified (100)Pt nanoparticles. The band for $\mathrm{CO}_{2}$ can be clearly observed at $0.1 \mathrm{~V}$, and the $\mathrm{CO}_{\mathrm{ads}}$ band is absent for all the spectra, pointing out that $\mathrm{Tl}$ enhances the electrocatalytic activity (Fig. 4a) by hindering the poisoning pathway thus allowing formic acid oxidation to proceed through the direct pathway, which also explains why $\mathrm{CO}_{2}$ is formed at low potentials.

\section{Effect of formic acid concentration}

Once the catalytic effect of $\mathrm{Tl}$ over Pt nanoparticles for formic acid oxidation has been confirmed, experiments using different formic acid concentrations were also performed with the maximum $\mathrm{Tl}$ coverage to evaluate its possible effect on the electrocatalytic activity. The corresponding potentiodynamic responses are shown in Fig. 9, for both (100)Pt and (111)Pt nanoparticles. In the two cases, current densities increase with the concentration of formic acid, especially at low potentials. In principle, it would be expected that currents were directly proportional to the concentration of formic acid, that is, $j \propto C_{\mathrm{o}}{ }^{*}$. Thus, the representation of $\log (j)$ at a given potential $v s$. $\log \left(C_{\mathrm{o}}^{*}\right)$ should be linear with a slope of 1 , the expected reaction order for the formic acid concentration. The plots are linear in the range between 0.2 and $0.7 \mathrm{~V}$ in both scan directions (inset of Fig. 9b). However, the slope is $0.75 \pm 0.03$ in this potential range for both electrodes, which would indicate that the reaction order is 0.75 . This fact clearly suggests that the reaction mechanism is complex. It could be argued that the complexity is due to the presence of the two routes for the reaction. However, it is known that the CO formation reaction occurs in the potential window lower than $0.5 \mathrm{~V}^{26}$ Thus, the oxidation reaction in the negative scan at $E>0.5 \mathrm{~V}$ would take place on a clean surface and only through the active intermediate. Moreover, the presence of $\mathrm{Tl}$ has suppressed the route through CO significantly. The constant value for the reaction order in the whole range, then, suggests that the complexity is not due to the $\mathrm{CO}$ route, but there is an intrinsic factor in the direct oxidation route. This fact would indicate that an additional species (not only formic acid) is involved in the reaction mechanism.

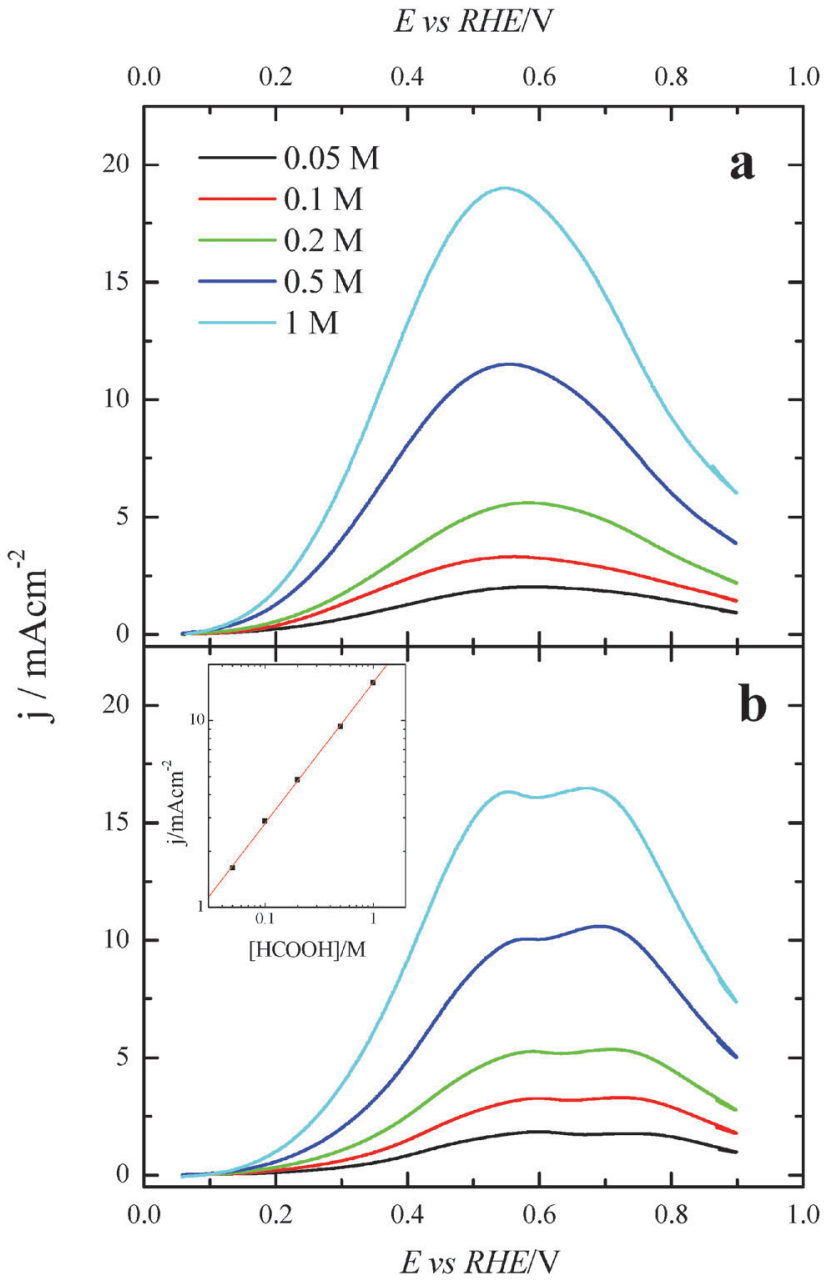

Fig. 9 Positive sweep voltammetric profiles for (a) (100)Pt and (b) (111)Pt nanoparticles with maximum $\mathrm{Tl}$ coverage in different concentrations of formic acid in $0.5 \mathrm{M} \mathrm{H}_{2} \mathrm{SO}_{4}$. Scan rate: $0.02 \mathrm{~V} \mathrm{~s}^{-1}$. Inset: double logarithmic plot of the current density at $0.5 \mathrm{~V}$ for the (111)Pt nanoparticles $\mathrm{Vs}$. formic acid concentration.

Additional evidence on that is found in the chronoamperometric responses after $600 \mathrm{~s}$ of reaction at $0.2 \mathrm{~V}$ for both nanoparticles at maximum $\mathrm{Tl}$ coverage at different formic acid concentrations (Fig. 10). In the case of (100)Pt nanoparticles (Fig. 10a), there is nearly no clear difference between the final current density for $0.05 \mathrm{M}$ and $0.1 \mathrm{M}$ (around 0.015$0.020 \mathrm{~mA} \mathrm{~cm}^{-2}$ ), but for the other concentrations, current density increases with the amount of formic acid in solution, increasing up to $0.145 \mathrm{~mA} \mathrm{~cm}^{-2}$ for $1 \mathrm{M}$ formic acid concentration. A similar behavior was observed for (111)Pt nanoparticles in Fig. 10b, with a final current density of $0.049 \mathrm{~mA} \mathrm{~cm}^{-2}$ for $1 \mathrm{M}$ formic acid. As for voltammetric curves, chronoamperometric currents become higher when the concentration of formic acid increases. Fig. 11 summarizes the differences observed for the final current density after $10 \mathrm{~min}$ at $0.2 \mathrm{~V}$ for both samples at maximum coverage, clearly indicating that the Tl-modified (100)Pt nanoparticles are much more active than the (111)Pt nanoparticles in the range of $\mathrm{HCOOH}$ concentration under study (0.05-1 M HCOOH). Currents recorded after 10 minutes reflect a nearly stationary situation. 


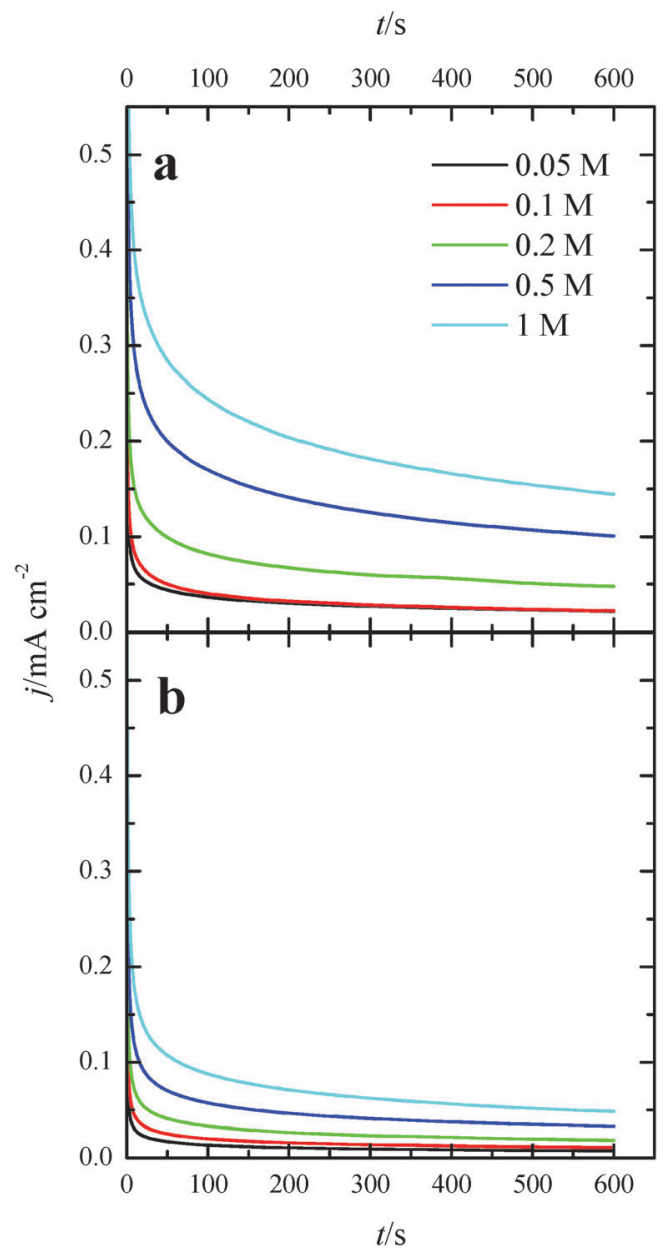

Fig. 10 Current transients for (a) (100)Pt and (b) (111)Pt nanoparticles with maximum $\mathrm{Tl}$ coverage recorded at $0.20 \mathrm{~V}$ for different formic acid concentrations in $0.5 \mathrm{M} \mathrm{H}_{2} \mathrm{SO}_{4}$.

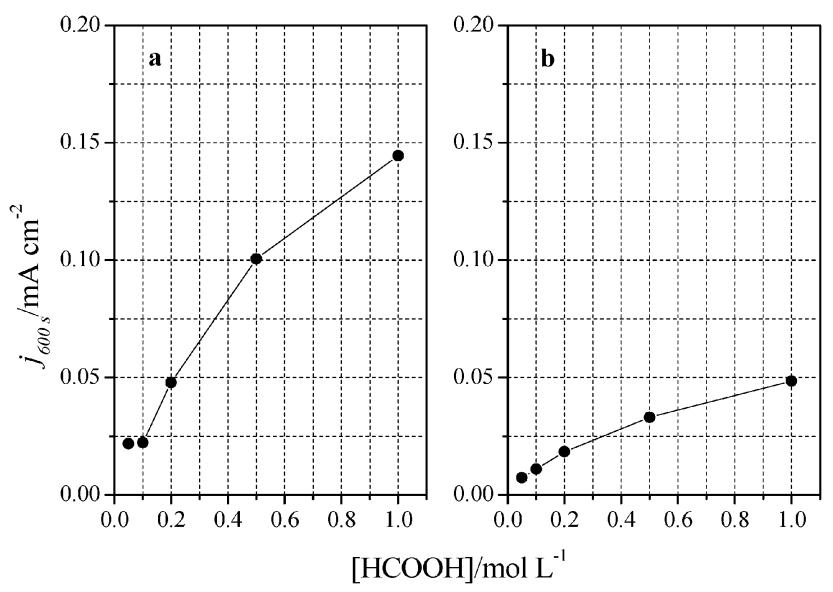

Fig. 11 Comparison between formic acid concentrations and current densities obtained after 10 minutes at 0.2 V. Data extracted from Fig. 9 for (a) (100)Pt and (b) (111)Pt nanoparticles.

For the currents at $10 \mathrm{~min}$ the reaction order is similar to that measured by voltammetry, which reinforces the fact that the reaction mechanism through the active intermediate is complex.

\section{Conclusions}

The deposition of $\mathrm{Tl}$ on (100)Pt and (111)Pt nanoparticles remarkably improves their electrocatalytic activity towards formic acid oxidation, especially in the low potential region. The activity enhancement is also dependent on the surface structure of the Pt substrate. In agreement with fundamental data from Pt single crystal studies, the use of (100)Pt nanoparticles is clearly more beneficial than the use of (111)Pt nanoparticles. Voltammetric and in situ FTIR data indicate that Tl decoration prevents the formation of adsorbed $\mathrm{CO}_{\mathrm{ads}}$. Consequently, it can be concluded that the enhancement of formic acid oxidation with $\mathrm{Tl}$-decorated platinum nanoparticles (especially with (100)Pt nanoparticles) is due to the hindrance of the indirect pathway (third body effect). So, the reaction mainly takes place through the direct pathway (via non- $\left.\mathrm{CO}_{\mathrm{ads}}\right)$. However, electronic effects cannot be discarded, due to the diminution of the onset potential for the formic acid oxidation reaction.

\section{Acknowledgements}

This work has been financially supported by the MICINN (Spain) (project CTQ2010-16271) and Generalitat Valenciana (project PROMETEO/2009/045 - FEDER). Farias M.J.S. would also like to thank CNPq, Brazil.

\section{References}

1 C. Rice, R. I. Ha, R. I. Masel, P. Waszczuk, A. Wieckowski and T. Barnard, J. Power Sources, 2002, 111, 83-89.

2 N. V. Rees and R. G. Compton, J. Solid State Electrochem., 2011, 15, 2095-2100.

3 S. Uhm, H. J. Lee and J. Lee, Phys. Chem. Chem. Phys., 2009, 11, 9326-9336.

4 G. Q. Lu, A. Crown and A. Wieckowski, J. Phys. Chem. B, 1999, 103, 9700-9711.

5 V. Grozovski, V. Climent, E. Herrero and J. M. Feliu, Phys. Chem. Chem. Phys., 2010, 12, 8822-8831.

6 C. Rice, S. Ha, R. I. Masel and A. Wieckowski, J. Power Sources, 2003, 115, 229-235.

7 A. Capon and R. Parsons, J. Electroanal. Chem., 1973, 45, 205-231.

8 M. Osawa, K. Komatsu, G. Samjeske, T. Uchida, T. Ikeshoji, A. Cuesta and C. Gutierrez, Angew. Chem., Int. Ed., 2011, 50, 1159-1163.

9 A. Cuesta, G. Cabello, M. Osawa and C. Gutiérrez, ACS Catal., 2012, 2, 728-738.

10 Y. X. Chen, M. Heinen, Z. Jusys and R. J. Behm, Langmuir, 2006, 22, 10399-10408.

11 J. M. Feliu and E. Herrero, in Handbook of Fuel Cells Fundamentals, Technology and Applications, ed. W. Vielstich, H. Gasteiger and A. Lamm, John Wiley \& Sons, Ltd., Chichester, 2003, vol. 2.

12 E. Herrero, A. Fernández-Vega, J. M. Feliu and A. Aldaz, J. Electroanal. Chem., 1993, 350, 73-88. 
13 E. Leiva, T. Iwasita, E. Herrero and J. M. Feliu, Langmuir, 1997, 13, 6287-6293.

14 S. G. Sun and Y. Y. Yang, J. Electroanal. Chem., 1999, 467, 121-131.

15 A. Cuesta, M. a. Escudero, B. Lanova and H. Baltruschat, Langmuir, 2009, 25, 6500-6507.

16 Y.-Y. Yang, S.-G. Sun, Y.-J. Gu, Z.-Y. Zhou and C.-H. Zhen, Electrochim. Acta, 2001, 46, 4339-4348.

17 S. P. E. Smith, K. F. Ben-Dor and H. D. Abruna, Langmuir, 1999, 15, 7325-7332.

18 H. W. Lei, H. Hattori and H. Kita, Electrochim. Acta, 1996, 41, 1619-1628.

19 F. J. Vidal-Iglesias, J. Solla-Gullón, E. Herrero, A. Aldaz and J. M. Feliu, J. Appl. Electrochem., 2006, 36, 1207-1214.

20 E. Herrero, M. J. Llorca, J. M. Feliu and A. Aldaz, J. Electroanal. Chem., 1995, 383, 145-154.

21 M. Shibata, N. Furuya, M. Watanabe and S. Motoo, J. Electroanal. Chem., 1989, 263, 97-108.

22 M. Watanabe and S. Motoo, J. Electroanal. Chem., 1975, 60, 275-283.

23 T. S. Ahmadi, Z. L. Wang, T. C. Green, A. Henglein and M. A. El-Sayed, Science, 1996, 272, 1924-1926.

24 F. J. Vidal-Iglesias, J. Solla-Gullón, P. Rodríguez, E. Herrero, V. Montiel, J. M. Feliu and A. Aldaz, Electrochem. Commun., 2004, 6, 1080-1084.

25 N. Tian, Z.-Y. Zhou, S.-G. Sun, Y. Ding and Z. L. Wang, Science, 2007, 316, 732-735.

26 V. Grozovski, J. Solla-Gullon, V. Climent, E. Herrero and J. M. Feliu, J. Phys. Chem. C, 2010, 114, 13802-13812.

27 P. Waszczuk, T. M. Barnard, C. Rice, R. I. Masel and A. Wieckowski, Electrochem. Commun., 2002, 4, 599-603.

28 F. J. Vidal-Iglesias, J. Solla-Gullon, E. Herrero, A. Aldaz and J. M. Feliu, Angew. Chem., Int. Ed., 2010, 49, 6998-7001.

29 Q. S. Chen, Z. Y. Zhou, F. J. Vidal-Iglesias, J. Solla-Gullon, J. M. Feliu and S. G. Sun, J. Am. Chem. Soc., 2011, 133, 12930-12933.

30 A. Saez, E. Exposito, J. Solla-Gullon, V. Montiel and A. Aldaz, Electrochim. Acta, 2012, 63, 105-111.

31 F. J. Vidal-Iglesias, A. López-Cudero, J. Solla-Gullón and J. M. Feliu, Angew. Chem., Int. Ed., 2013, 52, 964-967.
32 H. Lee, S. E. Habas, G. A. Somorjai and P. Yang, J. Am. Chem. Soc., 2008, 130, 5406-5407.

33 E. Casado-Rivera, Z. Gal, A. C. D. Angelo, C. Lind, F. J. DiSalvo and H. D. Abruna, ChemPhysChem, 2003, 4, 193-199.

34 M. D. Spasojevic, R. R. Adzic and A. R. Despic, J. Electroanal. Chem., 1980, 109, 261-269.

35 R. R. Adzic and M. L. Avramovivic, J. Electroanal. Chem., 1982, 134, 177-180.

36 A. Kelaidopoulou, E. Abelidou and G. Kokkinidis, J. Appl. Electrochem., 1999, 29, 1255-1261.

37 J. Clavilier, D. Armand, S. G. Sun and M. Petit, J. Electroanal. Chem., 1986, 205, 267-277.

38 J. Clavilier, K. El Achi, M. Petit, A. Rodes and M. A. Zamakhchari, J. Electroanal. Chem., 1990, 295, 333.

39 J. Solla-Gullón, F. J. Vidal-Iglesias, A. López-Cudero, E. Garnier, J. M. Feliu and A. Aldaz, Phys. Chem. Chem. Phys., 2008, 10, 3689-3698.

40 Q. S. Chen, J. Solla-Gullon, S. G. Sun and J. M. Feliu, Electrochim. Acta, 2010, 55, 7982-7994.

41 S. Chumillas, C. Busó-Rogero, J. Solla-Gullón, F. J. VidalIglesias, E. Herrero and J. M. Feliu, Electrochem. Commun., 2011, 13, 1194-1197.

42 T. Iwasita and F. C. Nart, Prog. Surf. Sci., 1997, 55, 271-340. 43 V. Grozovski, V. Climent, E. Herrero and J. M. Feliu, ChemPhysChem, 2009, 10, 1922-1926.

44 J. Solla-Gullón, P. Rodríguez, E. Herrero, A. Aldaz and J. M. Feliu, Phys. Chem. Chem. Phys., 2008, 10, 1359-1373.

45 Z. Y. Zhou, N. Tian, Z. Z. Huang, D. J. Chen and S. G. Sun, Faraday Discuss., 2008, 140, 81-92.

46 E. Herrero, V. Climent and J. M. Feliu, Electrochem. Commun., 2000, 2, 636-640.

47 J. Clavilier, J. P. Ganon and M. Petit, J. Electroanal. Chem., 1989, 265, 231-245.

48 R. R. Adzic, J. X. Wang, O. M. Magnussen and B. M. Ocko, J. Phys. Chem., 1996, 100, 14721-14725.

49 C. Buso-Rogero, V. Grozovski, F. J. Vidal-Iglesias, J. SollaGullon, E. Herrero and J. M. Feliu, J. Mater. Chem. A, 2013, 1, 7068-7076.

50 D. K. Lambert, Electrochim. Acta, 1996, 41, 623-630. 